\title{
Median Rhomboid Glossitis Reported In Diabetic Patient - An Enigmatic Pathological Finding
}

Muhammad Arqam Najmi, Muhammad Shahrukh Khan Sadiq, Arsalan Khalid

\begin{abstract}
:
Median rhomboid glossitis is an unusual oral condition with a fascinating clinical presentation. It is typically located around the midline of the dorsum of the tongue appearing as a reddish, rhomboid area expressing in form of atrophy. The following case reported is of 47 year old male diabetic patient who visited BUMDC for regular dental check up consisting of case report literature review, discussion including insight regarding etiology and its association with diabetes mellitus, clinical presentation and management of the condition.
\end{abstract}

Keywords: Median rhomboid glossitis, Diabetes Mellitus, Fungal infection

\section{INTRODUCTION}

Median rhomboid glossitis (MRG) is a benign pathological condition characterized by central atrophy of the filiform papilla of the tongue ${ }^{1}$. It is also known as central papillary atrophy, posterior lingual papillary atrophy or posterior midline atrophic candidiasis ${ }^{2}$. MRG has acquired its name because of the salient features associated uniquely with its lesion. It is usually located around the midline of the posterior dorsum of the tongue, classically exhibits a quadrilateral shape resembling a rhombus or a diamond and microscopically demonstrates an inflammatory process with fungal infection ${ }^{3}$.

Clinically, the lesion is reported to be flat, well-demarcated, symmetric and area of depapillation that arises anteriorly to the circumvallate papillae. The surface can either be smooth, fissured, or lobulated. The tongue may exhibit a darker appearance or may have a white diffuse coating ${ }^{4}$.

The male predominance has been observed three times more often than females ${ }^{5}$. An average global prevalence of $0.01 \%$ $1 \%$ is reported annually ${ }^{6}$. In Indian population the prevalence ranges from 1.0-2.5\% according to the study of Goswami ${ }^{7}$. $0.7 \%$ of MRG cases were reported in Turkey ${ }^{8}$. On the other hand, one study middle eastern study reported its prevalence to be $4.8 \%$ in the region?

\section{CASE REPORT}

A 47 year old male patient visited dental OPD for regular

I Muhammad Arqam Najmi,
I Senior Lecturer, Department of Science of Dental
I Materials, Bahria University Medical \& Dental College I
I Muhammad Shahrukh Khan Sadiq,
Lecturer, Department of Oral Pathology,
I Bahria University Medical \& Dental College
I Arsalan Khalid,
I Lecturer, Department of Oral Medicine,
| Bahria University Medical \& Dental College
I Received: 15-05-18

dental checkup. The patient was known case of insulin dependent diabetes mellitus since 10 years. The patient was non-smoker healthy, fully dentulous. On history taking, the patient use to take Metformin and Gliperide. Clinical examination of mouth revealed a well demarcated rhomboid area of depapillation. It was located on the dorsal surface of tongue just anterior to circumvallate papillae. The surface was smooth and raised, the palatal mucosa was normal. The red patch was observed by the patient three months ago which was painless. A clinical diagnosis of median rhomboid glossitis was made. Due to its asymptomatic nature, no treatment was planned. He was reassured regarding the non- aggressive nature of the condition and follow up was recommended after three to six months.

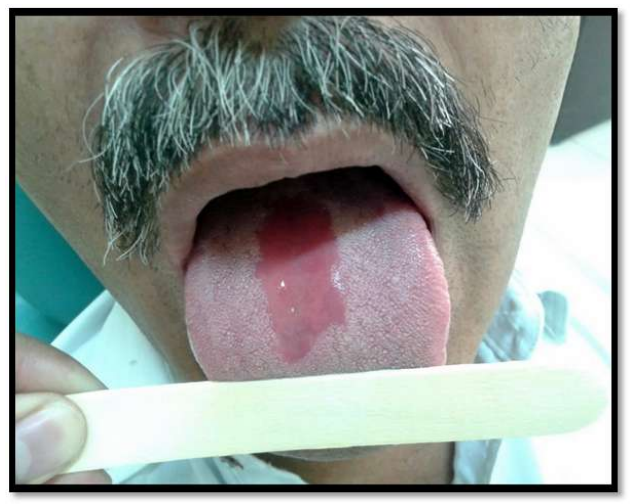

Figure 1: Median rhomboid glossitis

\section{DISCUSSION:}

MRG is a peculiar oral finding and rarely found in patients. Researches have shown that that in most cases it is usually asymptomatic $3,{ }^{10}$. However, but, in some cases may complain of persistent pain or irritation, has been reported ${ }^{11}$. MRG accompanied by the simultaneous inflammation of the palate due to immunosuppression is called the kissing lesion. The condition is considered as one of the significant markers of AIDS $^{12}$.

The etiology of MRG is controversial ${ }^{5,6}$. Historically, the Barghum in 1971 suggested the etiology of this disease is developmental in orign which may result due to failure of 
the lateral processes to envelope the tuberculum impar of the tongue during embryogeneis ${ }^{8,13}$. During the recent years, it has been considered as a variant of candidiasis in association with hyphae of fungal infection. Other possible suggested factors are diabetes, smoking, denture wearer, and use of corticosteroid sprays $^{9,13}$.

According to various studies, the prevalence of MRG was found to be higher in diabetics, immunosuppressed patients and patients on broad-spectrum antibiotics ${ }^{10,11}$. According to to Guggenheimer et al MRG is one of the most observed oral candidal infections in insulin-dependent diabetes mellitus patients ${ }^{11}$. The tongue lesions of atrophic nature were found in $26.4 \%$ of the diabetic patients and $91.7 \%$ of these lesions were MRG according to Farman et $\mathrm{al}^{8}$.

Under microscope, the bulbous, elongated epithelial rete ridges that showed a pattern resembling psoriasis, loss of the lingual papillae, parakeratosis of the epithelium, and inflammation are generally observed. The presence of candidal hyphae in the superficial epithelium is the diagnostic feature of $\mathrm{MRG}^{1}$. The differential diagnosis includes erythroplakia, geographic tongue, granular cell tumor gumma of tertiary syphilis, the granuloma of tuberculosis, deep fungal infections ${ }^{7,12,13}$.

\section{CONCLUSION:}

MRG is an enigmatic oral pathological condition with an idiopathic etiology. This condition has a strong affiliation with diabetes mellitus as reported in previous literature. The authors are of the view that updated extensive studies are a need of time to decipher the association of MRG with diabetes mellitus.

\section{REFERENCES:}

1. Goregen M, Miloglu O, Buyukkurt MC, Caglayan F, Aktas AE. Median Rhomboid Glossitis: A Clinical and Microbiological Study. European Journal of Dentistry. 2011;5(4):367-372.

2. Bojan A, Christy W, Kurian K, Elangovan S. A studyto determine the association between tobacco smoking habit and oral Candida! infection in median rhomboid glossitis by cytologic and histopahological method. J Indian Aca Oral Med Radiol. 2012;24(2): 106-12.

3. Lago-Méndez L, Blanco-Carrión A, Diniz-Freitas M, Gándara-Vila P, García-García A, Gándara-Rey JM. Rhomboid glossitis in atypical location: case report and differential diagnosis. Med Oral Patol Oral Cir Bucal 2005; 10:123-12

4. Rogers RS, 3rd, Bruce AJ. The tongue in clinical diagnosis. J Eur Acad Dermatol Venereol. 2004; 18:254-9.

5. Avcu N, Kanli A. The prevalence of tongue lesions in 5150 Turkish dental outpatients. Oral Dis. 2003;9:188-195.

6. Goregen M, Miloglu O, Buyukkurt MC, Caglayan F, Aktas AE. Median Rhomboid Glossitis: A Clinical and Microbiological Study. Eur J Dent. 2011;5(4): 367-372.

7. Panta P, Erugula SR. Median rhomboid glossitis developmental or candidal? Pan Afr Med J. 2015; 21: 221.

8. Goutzanis L, Vairaktaris E, Yapijakis C, Kavantzas N, Nkenke
E, Derka S, Vassiliou S, Acil Y, Kessler P, Stavrianeas N, Perrea D, Donta I, Skandalakis P, Patsouris E. Diabetes may increase risk for oral cancer through the insulin receptor substrate -1 and focal adhesion kinase pathway. Oral Oncol. 2007;43:165-73.

9. Ujpa'l M, Matos O, Bi'bok G, Somogyi A, Szabo G, Suba Z. Diabetes and oral tumors in Hungray: epidemiological correlations. Diabetes Care. 2004;27:770-4.

10. Jajarm H, Dastjerdi T. Assessment of prevalence of median rhomboid glossitis in diabetic patients referring to Mashhad. Diabetes Mellitus Research Centerin. 2005.

11. Guggenheimer J, Moore PA, Rossie K, Myers D, Mongelluzzo MB, Block HM, Weyant R, Orchard T. Insulindependent diabetes mellitus and oral soft tissue pathologies: II. Prevalence and characteristics of Candida and Candidal lesions. Oral Surg Oral Med Oral Pathol Oral Radiol Endod. 2000;89:570-6. Terai H, Shimahara M. Partial atrophic tongue other than median rhomboid glossitis. Clin Exp Dermatol. 2007;32: 381-4.

12. Soysa NS, Ellepola AN. The impact of cigarette/tobacco smoking on oral candidiasis: an overview. Oral Dis. 2005; 11:268-273.

13. Mirza D, Raza G, Abbasi A Z, Median rhomboid glossitis: a peculiar tongue pathology, report of a case and review of literature, International Journal of Pharmacy and Biological Sciences October 2016; 6(4):51-53. 